ISSN 0975-3311

Ushus JBMgt, 9, 1 (2010) 45-60

https://doi.org/10.12725/ujbm.16.5

\title{
CULTURAL INFLUENCES ON CORPORATE SOCIAL RESPONSIBILITY :
}

\author{
Jain Mathew* \& Jyothi Kumar**
}

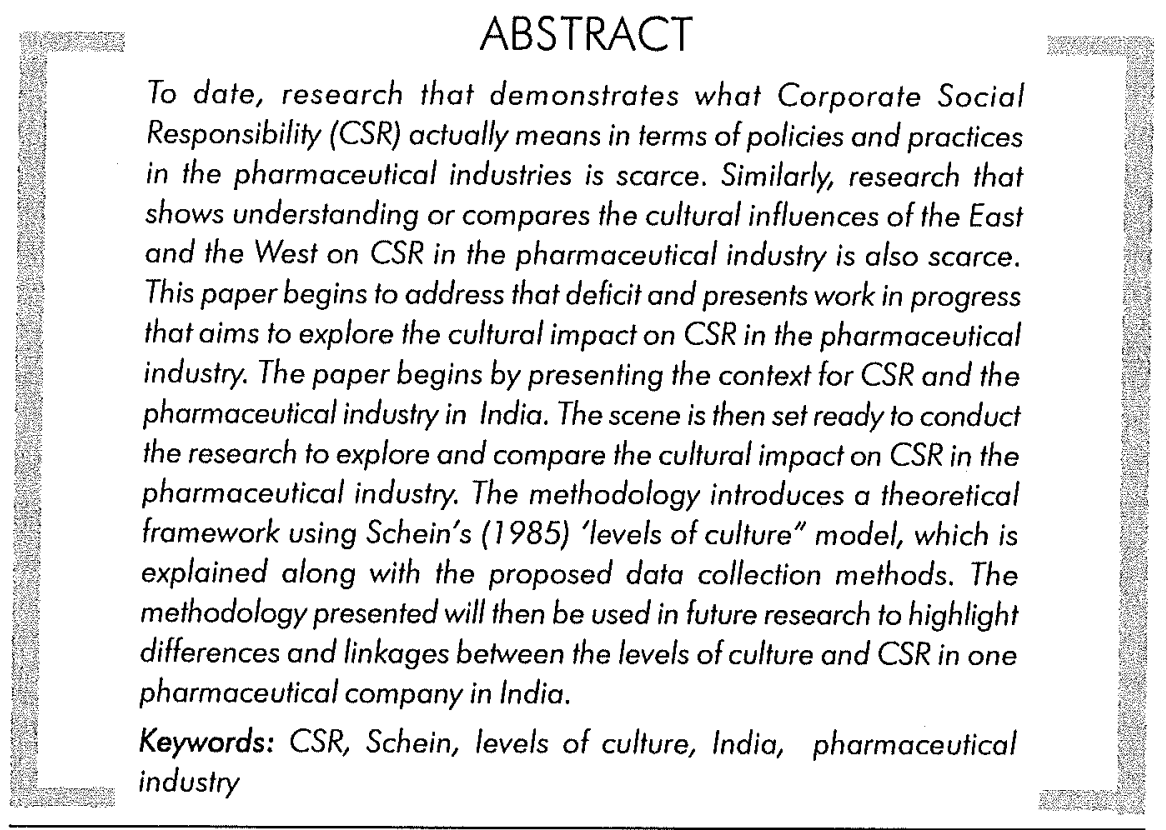

* Dept. of Management Studies, Christ University, Bangalore-29.

** Dept. of Management Studies, Christ University, Bangalore-29. 


\section{Introduction}

Many organizations like Novartis (2006) have incorporated a CSR stance in their mission or vision statement, or have stated endeavours of commitments to the environment and people such as Ranbaxy (2006) or making the "world a better place to live" via educational and healthcare programmes for example Alembic (2006). Some larger organizations can be seen devoting much of their corporate literature on their ethical and CSR stance for example GlaxoSmithKline (2006). More and more companies have ethical officers, CSR departments and ethical and CSR policies and use the reporting mechanism of the triple bottom line. As Crook (2005 p3) points out, "the movement for corporate social responsibility has won the battle of ideas". Moir (2003) agrees with Crook (2005) stating "CSR is here to stay".

However, Frankental (2001) argues that CSR is a vague term which can mean almost anything to anybody; whilst Crook (2005, p4) adds that in reality "CSR takes many different forms and is driven by many motives": Moir $(2003, p 7)$ adds to the debate by pointing out there is differing expectations of the nature of organizations responsibilities to society and for those organizations that do undertake CSR poses some key questions:

- What does it (CSR) actually mean?

- Responsibility for what?

- Responsibility to whom?

Accordingly, it can be seen that organizations do not possess any firm underpinning frameworks to guide them when undertaking CSR. According to Baker (2006), Development Director for Business in the Community, CSR is about how companies manage the business processes to produce an overall positive impact on society. As business organizations face the commercial need to satisfy not only their shareholders, but also a variety of internal and external stakeholders such as the government, customers, pressure groups, and local communities, there is an increasing expectation for these organizations to consider the environmental, economic and social impact of their activities, and implement Corporate Social Responsibility policies at home and abroad, in the case of international organizations.

As with most issues concerning International Business, it can be expected that CSR will be affected by the cultural values and attitudes of the people 
of different countries (Hill, 2005). Research acknowledges that different countries have different cultures. One of the main differences between India and the UK is that India is defined as having a more collective culture, where ties and relationships between people are close. In India society is built around extended families and the collective interest, whereas in the UK, a more individualist culture is found, where bonds and relationships between individuals are loose where personal freedom and achievement are valued greatly (Hofstede, 2001). It must be noted however that collective and individualistic cultures are stereotypes and there may indeed be individuals or groups within the dominant national cultures that present cultural identities different from the norm. So, what is the cultural impact on CSR in India? To date, the research available in this area remains sparse.

It is proposed that the focus of this study is at the organizational level with the individual's perception of CSR as understood and practiced in the organization, rather than what the individual perceives CSR ought to be.

The Indian Pharmaceutical sector is highly fragmented with more than 20,000 registered units. It has expanded drastically in the last two decades. The leading 250 pharmaceutical companies control $70 \%$ of the market with market leader holding nearly $7 \%$ of the market share. It is an extremely fragmented market with severe price competition and government price control. The pharmaceutical industry in India meets around $70 \%$ of the country's demand for bulk drugs, drug intermediates, pharmaceutical formulations, chemicals, tablets, capsules, orals and injectibles. There are about 250 large units and about 8000 Small Scale Units, which form the core of the pharmaceutical industry in India (including 5 Central Public Sector Units). These units produce the complete range of pharmaceutical formulations, i.e., medicines ready for consumption by patients and about 350 bulk drugs, i.e., chemicals having therapeutic value.

Following the de-licensing of the pharmaceutical industry, industrial licensing for most of the drugs and pharmaceutical products has been done away with. Manufacturers are free to produce any drug duly approved by the Drug Control Authority. Technologically strong and totally self-reliant, the pharmaceutical industry in India has low costs of production, low R\&D costs, innovative scientific manpower, strength of national laboratories and an increasing balance of trade. The Pharmaceutical Industry, with its rich scientific talents and research capabilities, supported by Intellectual Property Protection regime is well set to take on the international market. 
In common with all business sectors, the pharmaceutical industry is constantly scrutinised by stakeholders with regard to the manner of operations. CSR is a concept within the industry which is growing in importance, although there are many interpretations to what CSR is or should be.

Similarly, there is little research available to see what CSR actually means in terms of policies and practices in the pharmaceutical industries, nor an understanding of the cultural influences on the CSR in the pharmaceutical industry.

This paper begins by outlining the context of CSR and the pharmaceutical industry both in the India. It is regarded as important to highlight these different contexts which produce divergent approaches to CSR, where culture is identified as likely to impact on CSR in an international business context. The paper focuses on the pharmaceutical industry and therefore it will be necessary to provide a general background to the pharmaceutical industry in India. This exploratory research then investigates the comparison of the cultural impact on CSR in the pharmaceutical industry, highlighting differences and linkages between the levels of culture and CSR in one pharmaceutical company in India. To achieve this, a theoretical framework using Schein's (1985) "levels of culture" model is explained and is followed with detail of the methodology and data collection methods used.

\section{CSR and culture}

Frankental (2001) argues that CSR is an imprecise phrase, which can mean almost anything to anybody; as such when practised can mean many different things. It can often be seen that organizations do not possess any firm underpinning frameworks to guide them when undertaking CSR. In addition, businesses today face an increasingly commercial need to satisfy not only their shareholders, but also a variety of internal and external stakeholders such as the government, customers, pressure groups, and local communities, and there is an increasing expectation for these organizations to consider the environmental, economic and social impact of their activities, and implement CSR policies. As with most issues concerning businesses in an international context, it can be expected that CSR will be affected by the cultural values and attitudes of the people of different countries (Hill, 2005). 


\section{Theoretical framework}

This study proposes that a cultural perspective could be used to explore CSR in the pharmaceutical industry. However, there is no wholly accepted model of culture and the purpose of this paper is not to analyse the theoretical debate with regard to culture, but to explain the use of the theoretical framework adopted for this study - Schein's (1985) "levels of culture" model. Schein's framework will allow an analysis of those deeper underlying assumptions about CSR in the organization as well as analysis at other levels of culture. Assumptions are likely to be manifested through observable CSR policies and practices. Schein's model thus provides a framework for analysis that constructs a holistic view of CSR in the organization.

A widely accepted definition of culture is that given by Schein $(1985$, p. 9);

"... a pattern of basic assumptions - invented, discovered or developed by a given group as it learns to cope with its problems of external adaptation and internal integration- that has worked well enough to be considered valuable and therefore, to be taught to new members as the correct way to perceive, think and feel in relation to those problems."

Schein (2004) defines culture in terms of "shared basic assumptions" derived from "shared learning experiences". This then evolves as the correct way to perceive and behave in situations and becomes "the way we do things around here" (Deal and Kennedy, 1982, p4). Furthermore, according to Schein (2004), organizational culture will manifest itself as visible organizational structures and style, norms, values, rituals and climate. Values and beliefs of the organization, whether derived from initial founders or evolved from organizational leadership become the embodiment of the underlying organizational philosophy which will predict behaviour that can be observed. The strong binding element of an organizations culture is pur forward by Schein as the "basic underlying assumptions" which are explained as those which are so taken for granted that there becomes little variance where they tend to be non-confrontable and non-debatable. In order to analyse culture, Schein proposes levels of culture - the term level referring to the "degree to which the cultural phenomenon is visible to the observer".

Schein models the "levels of culture" with "artifacts", "beliefs and values", and "underlying assumptions", as three layers (Schein, 2004). The model 
is adopted as this study's analytical framework in order to analyse CSR as organizational assumptions; as manifested through these three levels and to compare the cultural manifestation of CSR, highlighting key issues. By using Schein's model as a theoretical framework, an understanding is possible of visible and invisible elements contributing the culture of CSR within the organization, in addition to those observable and measurable elements of organizational cultural CSR constructs,.

Artifacts - This level of analysis includes visible products of the organization, where CSR can be observed in the "physical environment", "technology and products", organizational style, myths, stories, rituals and ceremonies, organizational structure and processes.

Espoused beliefs and values - Beliefs may be formed as a response to past responses and learning of what is successful or not so. Schein (2004) acknowledges that some values such as those dealing with ethical elements may not be able to be tested, although via social validation may achieve some form of consensus. Social validation in this context is explained by Schein $(2004$, p29) as a mechanism whereby certain values may not be provable, however, by sharing and reinforcing them, they come to be taken for granted. Often it is these beliefs and values that con come to be gradually transformed into "non-discussible assumptions" which in turn become stated as sets of norms and "operational rules of behaviour". Schein (2004) gives a note of warning here, where it is pointed out that a distinction can be made between espoused values what people say they do with what they actually do. This contradiction can arise when there is little congruence with underlying assumptions, where the approach may be one which is more aspirational than actual. Beliefs and values about CSR at this level, will allow some prediction of behaviours that can be visible at the above artefacts level.

Basic underlying assumptions - as defined by Schein (2004), are assumptions held in the organization with little difference displayed, as they have been totally taken for granted.

Schein's framework allows an analysis of those deeper underlying assumptions about CSR in the organization which together with the other levels will provide an analysis that constructs a holistic view of CSR in the organization. The UK Government aims to transform CSR to being integrated into an organizations core values, strategy and operations and not just be seen as an "add on" (Timms, 2004). Accordingly, this analytical framework analyses 
those cultural elements affecting CSR within the organization, which in turn evolve with CSR becoming embedded into organizational culture and manifested in values, operations, and rituals. These effects can be studied with a comparison made of the cultural impact on CSR between India and the UK and India in the pharmaceutical industry.

\section{CSR - Indian context}

The CSR frameworks of companies, which are front-runners, have evolved over a period of time. Their specific approaches and strategies are based on the ethical beliefs of the founding fathers, (Tata, 1980) business areas in which the companies operate, the socio-economic environment, and the opportunities emerging over long periods of their existence.

Developing economies like India faces complex socio economic challenges during the times of Globalization. Within the context of Globalization, the role of the corporation in society is changing. The traditional assumption that the business of a business is to make profits (Friedman, 1970) changes to the belief that drivers of business success are not the traditional drivers of quality or price or convenience alone. Other variables like business practices, employee treatment, community engagement and the environment become important (Jose, 2003). As India moves towards a market-driven business environment, there is greater reliance on corporate support to society, increased awareness of the problems of wealth distribution and the growth of the volunteer sector and the Non Government Organisation (NGO) movement. It is also considered essential that businesses need to join hands with the state to compliment the socio economic needs of the country (TERI, 2004).

Traditionally the state has played a dominant role in the development process in India. The 1990's were characterised by the retreat of the state with the advent of market liberalisation and privatisation. Although the state still plays a pivotal role in the development process, one of the major problems with the state activities is that most programs quickly become embroiled in political manipulation, corruption, communal overtones and bitter in-fighting (Konana, 2006).

Sustainability as an aspect is more relevant as the opportunities for corporations in India are quite different from those of developed countries. In developed countries with strong governments, and some form of social 
security, the focus is on limiting the negative environmental impact of industrial activities rather than problems of the underprivileged. Corporations in developing countries like India need to address problems, which are development oriented in a more holistic manner (Hoekstra, 2003). It is in this context that the need for Public-Private partnership with well-defined controls and processes for the best use of resources for social change gains importance. "Social reforms driven by the community will bring people together, turn the attention of the masses to task that benefit society and reinforce peace and harmony" (Konana, 2006, p. 10).

Corporations also serve the community through the concept of fair product distribution. There is growing evidence that global companies can serve the poor more efficiently and provide better products and services at a lower cost and at a profit. This will involve corporations to decide products/ services for the enormous population at the bottom of the pyramid. The basic assumption is that this population segment has some disposable income and firms can still make profits at large volume (Prahalad and Hammond, 2002).

CSR in India today is seeing a paradigm shift from charity to a more holistic approach. In this context the idea of CSR requires fundamentally a new approach and outlook, which can be seen in table 1:

\section{Table 1: The New Approach To CSR}

(Table explained below)

\begin{tabular}{|c|c|c|}
\hline \multicolumn{2}{|c|}{ Creating New Mindset } \\
\hline $\begin{array}{c}\text { Person centric and opportunistic } \\
\text { Single goal- profit syndromes }\end{array}$ & Beyond management & $\begin{array}{c}\text { Building self-reliance } \\
\text { Process and brand driven } \\
\text { Multiple goals paradigm }\end{array}$ \\
\hline \multicolumn{2}{|c|}{ Creating New Programming Paradigm } \\
\hline $\begin{array}{c}\text { Social benefits - activity } \\
\text { Funding - dependence } \\
\text { and loyalty } \\
\text { Sporadic activity } \\
\text { Short term - immediate results }\end{array}$ & To governance & $\begin{array}{c}\text { Human excellence - enablement } \\
\text { Involve in building livelihoods } \\
\text { A continuous partnership }\end{array}$ \\
\end{tabular}

The above representation indicates the changes possible in terms of creating a new mindset. CSR can be much more than charity and welfare of the previous era. It is about the creation of self-reliance and moving from 
person centric, single goal perspective to process driven and multiple goal paradigms. For example, in the Indian context rural artisans create products, which are aesthetically valued but lack the necessary marketing, which will facilitate adequate rewards. In place of charity and welfare through funding present in the old paradigm the Corporation can work towards building self reliance by using the rural artisans products as corporate gifts or use them as interior decorations which may have more socially redeemable value. This will not only sustain the traditional industry and provision for livelihood but will also create continuous partnership, and serve the longterm goals of the organization which will facilitate human excellence. This model can be extended further in terms of corporate spending outside the large cities. Additionally, large corporations can exploit hundreds of historical places and villages for conducting corporate training, conferences and get-aways (Konana, 2006).

The public sector in India was conceptualized as a potent instrument of socio-economic development with a view to develop sound agricultural and industrial base, overcome economic and social backwardness and for generating sufficient surpluses (Hazari and Oza, 1970). Social upliffing was one of the major considerations, which favoured setting up of the public sector. Although with the passage of time, a sea change has taken place in the industrial scenario, socio-economic development of the local area still remains a major responsibility of the public as well as the private sector.

Along with the public sector, the private sector has played an important role in terms of CSR. In recent times a number of foundations set up by leading Indian firms, including Infosys, Wipro, Tata's, TVS, BIOCON and Dr. Reddy's Laboratory have taken keen interest in corporate activism to improve health care, education, living conditions, and reduce poverty (Sandhya, 2006). These foundations support numerous Government programs and have developed processes and methodologies for effective change.

Many "Top 100" organizations view CSR as a comprehensive set of policies, practices and programmes that are integrated throughout business operations and decision making processes that are supported and rewarded by top management (Coyle, 2004).

It is now recognised that companies should not solely pursue profit and that societies' needs should be paramount. Organizations should pursue stakeholder interests whenever possible. A Friedmanite view of the 
organization would present finance as the predominant feature, but this is no longer appropriate, which is increasingly taking an inclusive view of business. Indeed, Castka et al (2004) argue that companies require the profits gained from CSR to be in equilibrium with the demand for CSR from stakeholders. In line with those views, many organizations are moving from "Bottom line" reporting to "Triple line reporting" which includes not only profit but also social and environmental performance (Mallin, 2004).

Institutional investors have brought pressure to bear on organizations to report on CSR policies. Coyle (2004) suggests;

1. That Annual report and accounts should disclose that social interest and reputations have been considered

2. A socially responsible investment service to be developed providing a service relating to an organizations environment and ethical issues

3. There is a significant link between quality assurance, corporate governance and CSR, probably through the strategic and business planning process.

Adding to this, Whitehouse (2006, p. 281) points out that the information with regard to corporate CSR policies now available to the public has become "increasingly significant in light of the substantial growth of in recent years of socially responsible investment (SRI)". However, Whitehouse (2006) does state that questions arise about the capability of corporations to implement CSR policies that are based upon a vague concept, with regard to the definition of CSR used by people who seem committed to using CSR and the subsequent preferred methods of implementation of CSR policies.

Developments in CSR have been assisted by a benchmarking service (Coyle, 2004). This is where organizations can have their CSR policies assessed and compared with other organizations to establish CSR performance measurement guidelines. This CSR index is published by Business in the Community (BITC) and shows an organizations CSR strategies; the success of integrating into operations and the practices around the success in relation to the major stakeholders. Each additional publication is expected to include more companies, who are aware of the potential to achieve some advantage to their public image (Coyle, 2004).

CSR sustainability reporting is a relatively new development and organizations are encouraged to plan for CSR integration into strategy and show the 
development of the policy over time and how this will affect the major stakeholders and the organizations main purpose (Coyle, 2004). Many of these approaches can be incorporated in an organizational Operating and Financial Review to show a deeper understanding of the impact on society, but a general approach to the inclusion in strategy is seen as a major future development (Mallin, 2004).

Reinforcing organizational movements toward CSR strategies, the Government "aims to transform CSR from being seen as an "add on" to being a core part of business practice for more and more organizations" (Timms, 2004). However, CSR as it is understood seems to mean different things to different people and hence CSR as practised, when based upon a vague concept (Whitehouse, 2006), is not a consistently understood phenomena across organizations.

\section{Methodology}

The previous sections on CSR and the pharmaceutical industry suggest that there is limited assistance in the identification of the cultural impact of CSR in the pharmaceutical industry in India. Consequently it is necessary to undertake an exploratory empirical study to gain information which will provide some insight into this issue.

A case study approach is adopted for this study, as Yin (2003) acknowledges that the case study approach can be used in organizational and management studies to help appreciate the complexity of the organizational phenomena, which in this study is CSR entwined within levels of culture (see table 2).

Table 2: The Framework For Analysis

\begin{tabular}{|c|c|}
\hline Observation & Artifacts \\
Analysis of data & Espoused beliefs and values \\
Questionnaires & Underlying assumptions \\
Semi-structured interviews & \\
\hline
\end{tabular}

\section{Data collection}

As previously stated, there is no universally accepted definition of CSR, however there is some agreement found in codes of practice. The Council 
of Fair Business Practices (CFBP) founded in Western India, has as point 12 in the code;

"... discharging social responsibilities and the responsibility to protect the environment and nature's infrastructure environment" (Chakraborty, 1997)

and comments made by the UK Chancellor of the Exchequer such as;

"[with regards to CSR] ... brand names depend not only on quality, price and uniqueness but on how, cumulatively, they [the companies] interact with companies' workforce, community and environment." (Brown, 2004).

Furthermore, this study adopts the following understanding of CSR as a basis for framing some of the questions and observations in the process of data collection;

"... conducting the business of an organization in a manner that meets high social and environmental standards" (Fisher and Lovell, 2006 p. 51).

Friedman (1970) argues that the only social responsibility is to increase profits. This is now the prevailing classical opposing view to CSR and thus is also included as a basis for framing some of the questions and observations in the process of data collection. Finally, external roles that impact on CSR and the reality of implementing CSR for organizations are explored. This is because a theme that pervades the literature concerns the perceived tension between public interest and private profit (Crook, 2005 p. 11) and that theme will form the basis from which to frame some of the questions and to analyse observations.

The three levels in Schein's (2004) model require appropriate data collection methods for each level and replication in one company.

Artifacts- data collection for this level will be observation of the "phenomena that one sees, hears, and feels when one encounters a new group with an unfamiliar culture". With regard to CSR the phenomena are presented, but not limited to those, in table 3. 
Table 3: Observable Phenomena

(adapted from Schein, 2004)

\begin{tabular}{|l|l|l|l|}
\hline Phenomena & $\begin{array}{l}\text { Physical } \\
\text { Environment }\end{array}$ & Artistic Creations & Values \\
\hline $\begin{array}{l}\text { Expressed In } \\
\text { Observable } \\
\text { Examples }\end{array}$ & $\begin{array}{l}\text { buildings } \\
\text { language } \\
\text { technology } \\
\text { products }\end{array}$ & $\begin{array}{l}\text { company style clothes } \\
\text { manners of address } \\
\text { emotional displays } \\
\text { myths and stories }\end{array}$ & $\begin{array}{l}\text { published lists rituals } \\
\text { behaviour of } \\
\text { members company } \\
\text { processes }\end{array}$ \\
\hline
\end{tabular}

Espoused beliefs and values - data will be analysed to explore the relationship of CSR with elements such as strategies, goals, philosophies and records of behaviour with some attention paid to the match between what is said and what is actually done in the organization.

Underlying assumptions - data will be collected for this level through the use of semi-structured interviews and questionnaires. Schein (2004, p. 31) states that these basic assumptions "have become so taken for granted that there is little variance within a social unit". The questionnaires are to be administered to various stakeholders, plus semi-structured interviews will be used to ascertain what these basic assumptions towards CSR in the organization are.

Questionnaires and semi structured interviews have already been devised using the concept of CSR which encompasses social and environmental approaches, Friedmanite views, external roles and company obligations, the tension of implementation of CSR with profit demands and a general exploration of the relationship between ethics and CSR within the organization.

Table 4: Questionnaire Overview

\begin{tabular}{|c|l|}
\hline $\begin{array}{c}\text { Number of } \\
\text { items }\end{array}$ & $\begin{array}{l}\text { The respondents' understanding and actions with regard } \\
\text { to understanding of organizational response to: }\end{array}$ \\
\hline 4 & $\begin{array}{l}\text { Community and social impacts } \\
\text { Environmental issues }\end{array}$ \\
4 & $\begin{array}{l}\text { Extent to which CSR generally as an item is addressed } \\
\text { by the organization }\end{array}$ \\
4 & $\begin{array}{l}\text { External roles and company obligations to CSR } \\
\text { Reality of implementation of CSR }\end{array}$ \\
\hline
\end{tabular}

A 5 point Likert scale was used in the questionnaires $(0=$ strongly disagreed to $4=$ strongly agreed) 
Semi-structured interviews will be used as a method to obtain richer data concerning the deeply held assumptions of the respondent of CSR in the organization, In order to allow respondents to relate freely their thoughts and feelings about CSR, open-ended interviews will be used to gather data about the respondents' understandings and assumptions about CSR.

\section{Conclusions}

The scope of the research has been introduced and a background to the pharmaceutical industry in India. The link between culture and CSR has been established in Business operations and a theoretical framework of Schein's levels of culture explained. CSR in an Indian context has yet to be been explored, although a suitable methodology, with appropriate data collection procedures, for each level of culture has been presented. The research is now at the data collection stage. Upon completion, discussion of the results, analysis and conclusions will be drawn. Differences and linkages between the levels of culture in one pharmaceutical company in India will be made. The importance and implications of these for the companies and research is noted, as companies who propose to operate in different cultural environments will need to take account of differences in cultures when implementing CSR policies.

Although, the proposed study is a small scale it is likely to provide interesting insights despite limitations of scope. To date cross-cultural comparisons of pharmaceutical companies are scarce, hence the study will provide new and interesting understandings. Importantly, this study provides a platform from which to conduct further comparisons with similar pharmaceutical companies in other cultures.

\section{References}

Alembic (2006) Commitment to Life hitp://www.alembic-india.com/aboutus.asp accessed $21^{\text {si }}$ August 2006.

Baker, M. (2006) "Corporate Social Responsibility - What Does it Mean?" http:// www.Mallenbaker.net accessed 21"January 2006.

Brown, G. (2004) The Rt HonMP, Chancellor of the Exchequer quoted in CSR Academy (2004) The CSR Competency Framework. Crown Copyright. Department of Trade and Industry. 
Business for Social Responsibility (2006) Overview of Corporate Social Responsibility http://www.bsr.org/CSRResources/IssueBriefDetail.cfm? DocumentID =48809 accessed $7^{\text {th }}$ September 2006.

Castka, P., Bamber, C. J., Bamber, D. J., and Sharp, J. M. (2004) Integrating corporate social responsibility (CSR) into ISO management systems-in search of a feasible CSR management system framework The TQM Magazine 16[3] pp. 21 6-224.

Chakraborty, K. S. (1997) Business ethics in India Journal of Business Ethics 16, pp. 1529. 1538.

Crook, C. (2005) A Survey of Corporate Social Responsibility The Economist $22^{\text {nd }}$ January 2005.

CSR Academy (2004) The CSR Competency Framework. Crown Copyright. Department of Trade and Industry, UK.

Coyle, B. (2004) Corporate Governance. 2 ${ }^{\text {nd }}$ Edition. ICSA Publishing.

Deal, T. E. and Kennedy, A. A. (1982) Corporate Culture: The Rites and Rituals of Corporate Life. Reading Mass: Addison Wesley.

Department of Health (2006)

hHtp://mww.dh.gov.uk/PolicyAndGuidance/MedicinesPharmacyAndlndustry/IndustryBranch/ IndustryBranchArticle/ts/en?CONTENT_ID $=4000038 \&$ chk=i5QMGJ accessed $25^{\text {th }}$ April 2006.

Fisher, C. and Lovell, A. (2006) Business Ethics and Values $2^{\text {nd }}$ Edition. Prentice Hall.

Frankental, P. (2001) Corporate social responsibility - a PR invention? Corporate Communications: An International Journal, 6 [1], pp. 18-23.

Friedman, M. (1970) The social responsibility of business is to increase profits. New York Times Magazine, 13 $3^{\text {th }}$ September 33, pp. 122-126.

GlaxoSmithKline (2006) Responsibility http://www.gsk.com/responsibility/index.htm accessed 25 2 tuly 2006.

Hazari, R. K. and Oza, A. N. (1970) 'Public Sector in India' in Robinson, E. A. G. and Kidron, M. (1970) (eds) Economic Development in South Asia, London.

Hill, C. (2005) International Business: Competing in the Global Marketplace $5^{\text {HI }}$ International Edition. London: McGraw-Hill.

Hoekstra, B. (2003) 'CSR and the IT industry in Bangalore: Observations of a practitioner'. IIMB Management Review, December 2003, pp. 78-81.

Hofstede, G. (2001) Culture's Consequences $2^{\text {nd }}$ Edition. Sage Publications: London.

Jose P. D., Bandi R., and Mehra M. (2003) 'Corporate social Responsibility and the information and communication technology sector: Discussion' IIMB Management Review, December 2003, pp. 61-76. 
Konana, P. (2006) 'Towards Corporate Social Responsibility' The Hindu, March 9th , p. 10. Mallin, C. A. (2004) Corporate Governance $1^{\text {st }}$ Edition. Oxford University Press 2004.

Moir, L. (2003) The business world's latest buzz word? CSR and what it means to you. Strategic Direction 19 [6] p. 7.

Novartis (2006) Our Mission: http://www.novartis.com/about_novartis/en/ our_mission.shtm accessed $25^{\text {th }}$ July 2006.

Pharmaceutical and Drug Manufacturers (2006) Indian Pharmaceutical Industry Overview http://www.pharmaceutical-drug-manufacturers.com/pharmaceutical-industry/accessed $25^{\text {th }}$ April 2006.

Pharmiweb (2005) Why corporate social responsibility is healthy for pharma $21^{\text {st }}$ July 2005 http://www.pharmiweb.com/features/feature.asp?ROW ID $=630$ accessed $25^{\text {th }}$ July 2006.

Prahalad, C. K. and Hammond, A. (2002) 'Serving the poor profitably' Harvard Business Review, September 2002, pp. 48-56.

Ranbaxy (2006) Ranbaxy Laboratories Ltd hHtp://www.ranbaxy.com/ accessed $21^{\text {st }}$ August 2006.

Sandya, A. U. (2006) 'Corporate Social Responsibility', The Hindu, 9 9 August 2006, p. 21.

Schein, E. H. (1985) Organizational Culture and Leadership $1^{\text {st }}$ Edition. San Francisco: Jossey-Bass.

Schein, E. H. (2004) Organizational Culture and Leadership $3^{\text {rd }}$ Edition. San Francisco: Jossey Bass.

Tata, J. R. D. (1980) 'A matter of Expectation' Economic Times, 3' August, p. 11.

TERI, (2004) Citizens at Work: Indian Corporates in Social Setting, NewDelhi. pp. 1 - 14.

Timms, S. (2004) Minister for Energy, e commerce and Postal Services cited in CSR Academy 2004 The CSR Competency Framework. Crown Copyright. DTI.

Yin, R. K. (2003) Case Study Research Design and Methods 3rd Edition. Sage Publications.

Whitehouse, L. (2006) 'Corporate Social Responsibility: Views from the Frontline' Journal of Business Ethics 63, pp. 279-296. 